\title{
Effect of extended application time of universal adhesives on bond strength of brackets and enamel integrity
}

\author{
Efeito da extensão do tempo de aplicação de adesivos universais na resistência de união de \\ bráquetes e na integridade do esmalte \\ Efecto del tiempo de aplicación prolongado de los adhesivos universales sobre la fuerza de unión de \\ los brackets y la integridad del esmalte
}

Received: 09/20/2021 | Reviewed: 10/01/2021 | Accept: 10/06/2021| Published: 10/10/2021

\author{
May Anny Alves Fraga \\ ORCID: https://orcid.org/0000-0002-9323-0862 \\ University of Campinas, Brazil \\ E-mail: mayannyfraga@ hotmail.com \\ Daniela Feu Rosa Kroeff de Souza Laignier \\ ORCID: https://orcid.org/0000-0003-1734-4793 \\ University of Vila Velha, Brazil \\ E-mail: danielafeurosa@gmail.com \\ Carolina Sandra Garfias Yamashita \\ ORCID: https://orcid.org/0000-0002-0041-7506 \\ University of Campinas, Brazil \\ E-mail: carogy@gmail.com \\ Américo Bortolazzo Correr \\ ORCID: https://orcid.org/0000-0002-3306-7055 \\ University of Campinas, Brazil \\ E-mail: acorrer@unicamp.br \\ Licia Pacheco Teixeira \\ ORCID: https://orcid.org/0000-0002-8645-5211 \\ Federal University of Espirito Santo, Brazil \\ E-mail: liciapacheco@gmail.com \\ Juliana Malacarne Zanon \\ ORCID: https://orcid.org/0000-0001-7913-4973 \\ Federal University of Espirito Santo, Brazil \\ E-mail: jmalacarne@hotmail.com
}

\begin{abstract}
The objective of this study to evaluate the effect of universal adhesives application time to enamel through shear bond strength (SBS), adhesive remnant index (ARI), and morphological enamel integrity. Bovine incisors were divided into four groups according to bonding system protocol $(n=20)$ : (1) conventional etch-and-rise adhesive - Transbond XT Primer (P-XT); (2) one-step self-etching adhesive - Transbond Self Etching Primer (T-SEP); (3) one universal adhesive - Single Bond Universal, which were rubbed for 20s (SBU-20) or (4) 40s (SBU-40). Transbond XT composite was used to bond the brackets to enamel. SBS was evaluated in a universal test machine at $0.5 \mathrm{~mm} / \mathrm{minute}$. ARI was determined under x12.5 magnification and enamel damage was evaluated through scanning electron microscope (SEM) after debonding $(n=10)$. SBS data were compared using one-way ANOVA and Tukey's test. The Kruskal-Wallis test was used to compare the ARI scores $(\alpha=0.05)$. The P-XT and T-SEP groups showed significantly higher bond strength than SBU-20 and SBU-40 ( $\mathrm{p}<0.05)$. The ARI was similar for all groups $(\mathrm{p}>0.05)$. SEM showed enamel damage only in T-SEP and P-XT groups. Conventional 'etch and rinse' and 'self-etch' adhesives had the highest shear bond strength, but they were associated with more enamel damage compared to universal adhesives. The application of universal adhesives with the time recommended by the manufacturer — ensure satisfactory bond strength and enamel integrity.
\end{abstract}

Keywords: Orthodontic brackets; Dental bonding; Orthodontics.

\section{Resumo}

Avaliar o efeito do tempo de aplicação de adesivos universais no esmalte através da resistência ao cisalhamento (SBS), índice de adesivo remanescente (IRA) e integridade morfológica do esmalte. Métodos: Incisivos bovinos foram divididos em quatro grupos de acordo com o protocolo do sistema de colagem $(\mathrm{n}=20)$ : $(1)$ adesivo convencional de ataque ácido - Transbond XT Primer (P-XT); (2) adesivo autocondicionante de passo único Transbond Self Etching Primer (T-SEP); (3) adesivo universal - Single Bond Universal, que foi esfregado por 20s (SBU-20) ou (4) 40s (SBU-40). O compósito Transbond XT foi usado para colar os bráquetes ao esmalte. A SBS foi 
avaliada em uma máquina de ensaios universais a $0,5 \mathrm{~mm} /$ minuto. O IRA foi determinado com aumento de $12,5 \mathrm{x}$ e o dano ao esmalte foi avaliado em microscópio eletrônico de varredura (MEV) após a descolagem $(\mathrm{n}=10)$. Os dados SBS foram comparados usando ANOVA de uma via e teste de Tukey. O teste de Kruskal-Wallis foi usado para comparar os escores do ARI $(\alpha=0,05)$. Os grupos P-XT e T-SEP apresentaram resistência de união significativamente maior do que SBU-20 e SBU-40 ( $p<0,05)$. O IRA foi semelhante para todos os grupos ( $p>0,05)$. SEM mostrou danos ao esmalte apenas nos grupos T-SEP e P-XT. Os adesivos convencionais e autocondicionante de um passo apresentaram a maior resistência ao cisalhamento, mas foram associados a mais danos ao esmalte em comparação com os adesivos universais. A aplicação de adesivos universais com o tempo recomendado pelo fabricante - garante resistência de união e integridade do esmalte satisfatórias.

Palavras-chave: Bráquetes ortodônticos; Colagem dentária; Ortodontia.

\section{Resumen}

Evaluar el efecto del tiempo de aplicación de los adhesivos universales sobre el esmalte mediante resistencia al cizallamiento (SBS), índice de adhesivo remanente (IRA) e integridad morfológica del esmalte. Los incisivos bovinos se dividieron en cuatro grupos de acuerdo con el protocolo del sistema de unión $(\mathrm{n}=20)$ : (1) adhesivo de grabado convencional - Transbond XT Primer (P-XT); (2) adhesivo autograbante de un solo paso - Transbond Self Etching Primer (T-SEP); (3) adhesivo universal: Single Bond Universal, que se ha frotado durante $20 \mathrm{~s}$ (SBU-20) o (4) $40 \mathrm{~s}$ (SBU-40). Se utilizó el composite Transbond XT para unir los brackets al esmalte. El SBS se evaluó en una máquina de ensayo universal a 0,5 mm / min. El ARI se determinó con un aumento de 12,5x y el daño al esmalte se evaluó en un microscopio electrónico de barrido (SEM) después del desprendimiento $(n=10)$. Los datos de SBS se compararon utilizando ANOVA de una vía y prueba de Tukey. Se utilizó la prueba de Kruskal-Wallis para comparar las puntuaciones del ARI $(\alpha=0,05)$. Los grupos P-XT y T-SEP tuvieron una fuerza de unión significativamente mayor que SBU-20 y SBU-40 ( $\mathrm{p}<0.05$ ). El ARI fue similar para todos los grupos ( $>$ > 0.05). SEM mostró daño en el esmalte solo en los grupos T-SEP y P-XT. Los adhesivos autograbantes convencionales y de un solo paso tuvieron la mayor resistencia al cizallamiento, pero se asociaron con más daño al esmalte en comparación con los adhesivos universales. La aplicación de adhesivos universales con el tiempo recomendado por el fabricante garantiza una fuerza de unión e integridad del esmalte satisfactorias.

Palabras clave: Brackets de ortodoncia; Adhesión dental; Ortodoncia.

\section{Introduction}

It is essential that dental adhesives used to bond orthodontic brackets to enamel provide enough bond strength between them to prevent spontaneous dislodgments during treatment. Adhesives should also not induce damage to the enamel surface when removed (Lamper et al., 2014). The displacement of brackets during orthodontic treatment can occur due to an unsatisfactory bonding with dental structure, increasing treatment time and costs (Almosa \& Zafar, 2018). Occasionally, excessive forces on removing the orthodontic brackets may cause enamel damage (Meeran, 2013), as in, it is recommended that resin materials used on brackets bonding should stay adhered to the teeth surface after its intentional removal ${ }^{4}$.

Values of $6 \mathrm{MPa}$ and $8 \mathrm{MPa}$ have been reported to be suitable to tolerate masticatory forces as well as to preserve dental structure during brackets' removal (Alshahrani et al., 2018). Bond strength values higher than $12 \mathrm{MPa}$ revealed a $70 \%$ increase in the risk of enamel damage (Lamper et al., 2014), which is the case when using phosphoric acid 37\% (Ibrahim et al., 2020). Self-etching adhesives for specific use in orthodontics were developed to reduce the enamel damage, the complexity of bonding technique and to improve clinical time (Bayar \& Çokakoğlu et al., 2020). However, these adhesives need a low pH value to achieve enamel etching and retention patterns similar to those obtained with the established adhesive - acid etching systems. Thus, similar patterns of enamel damage have also been reported (Lamper et al., 2014).

A group of versatile adhesives, called "universal adhesives", can be applied in both conventional and self-etching techniques (Perdigão \& Swift, 2015). It is possible due to the distinguished composition of these products — based on the presence of MDP monomer, which is able to chemically adhere to different substrates. The ability of chemical bonding of MDP to hydroxyapatite promotes a long-lasting interaction (Carrilho et al., 2019) that may provide enough retention of brackets until the end of the treatment, and protection of the dental enamel structure.

Universal adhesives used without previous application of phosphoric acid, has shown to be less efficient on the bond strength to enamel compared to conventional adhesives and strong self-etching agents (Loguercio et al., 2015). Thus, an 
increase in the universal adhesives' application time has been recommended to enhance the bond strength to dental structure (Loguercio et al., 2015); however, it is not known so far if it may cause enamel damage.

Thus, the aim of this in vitro study was to evaluate the effect of universal adhesives application time on shear bond strength (SBS), adhesive remnant index (ARI), and enamel integrity of orthodontic brackets bonded to bovine enamel. The null hypotheses were: (1) there is no difference between shear bond strength (SBS) of the different adhesive protocols studied and; (2) the adhesive remnant index (ARI) distribution has no differences between the studied groups.

\section{Methodology}

\section{Specimen preparation}

This study was submitted to the Animal Ethics Committee (CEUA/UFES/0017-2017). Eighty newly extracted bovine teeth were used, which were stored for a maximum of 2 weeks in a $0.5 \%$ chloramine-T solution, at $4{ }^{\circ} \mathrm{C}$ in a fridge. The criteria for tooth selection included intact enamel, no cracks, no gross damage (10x magnification) and no caries.

The teeth were cleaned and polished with pumice and rubber prophylactic cups for 30 seconds, and embedded on a PVC ring (Tigre, Joinville, SC, Brazil) filled with Durone type IV gypsum (Dentsply, York, Pennsylvania, USA), exhibiting the crown on the top of the cylinder. The bonding area $\left(14.31 \mathrm{~mm}^{2}\right.$;) was delimited with an adhesive paper (Velasquez et al., 2006).

The specimens were randomly separated and numbered into four groups of twenty specimens each. The enamel surfaces were carefully dried with oil-free compressed air at a distance of $10 \mathrm{~mm}$ for $5 \mathrm{~s}$. Table 1 lists the bonding protocol used for each group. The resin composite Transbond XT (3M Unitek, Seefeld, Germany) was applied on the mesh-base of metal brackets (Edgewise bracket for tooth 21; bonding area: $14.31 \mathrm{~mm}^{2}$; Morelli Ortodontia, Sorocaba, SP Brazil) that were pressed on teeth with a force of 200gf using a tensiometer (Morelli Ortodontia, Sorocaba, SP Brazil). The excess of resin composite was carefully removed and light-cured using a light emitting diode (LED Bluephase (Ivoclar Vivadent, Schaan, SWZ) with $1,200 \mathrm{~mW} / \mathrm{cm}^{2}$ irradiance and one exposure of 20 seconds in each side of the bracket (mesial and distal), for a total exposure time of $40 \mathrm{~s}$. The specimens were immersed in distilled water for $24 \mathrm{~h}$ at $37{ }^{\circ} \mathrm{C}$ until shear bond strength test. A single operator was responsible to perform all bonding procedures.

Table 1. Description of the studied groups.

\begin{tabular}{|c|c|c|c|}
\hline Group & Type of adhesive & Manufacturer & Application protocol \\
\hline & & & Etch enamel with $37 \%$ phosphoric acid gel for 15 \\
\hline P-XT & 2-step Transbond & 3M/ESPE, St. & $\mathrm{s}$; Rinse thoroughly for $30 \mathrm{~s}$; Apply one layer \\
\hline (Control Group) & Primer XT (P-XT) & Paul, MN, EUA & of Transbond XT adhesive; Gently air-dry for $5 \mathrm{~s}$; \\
\hline & & & Light cure for $20 \mathrm{~s}$ \\
\hline T-SEP & Transbond Self & 3M/ESPE, St. & Rub primer on the tooth for $5 \mathrm{~s}$; Gently air-dry for $5 \mathrm{~s}$; \\
\hline (manufacturer recommendation $\mathrm{E}$ & Etching Primer (SEP & Paul, MN, EUA & Light cure for $20 \mathrm{~s}$ \\
\hline SBU-20 & Single Bond & 3M/ESPE, St. & Rub primer on the tooth for $20 \mathrm{~s}$; Gently air-dry for $5 \mathrm{~s}$ \\
\hline (manufacturer recommendation & Universal (SBU) & Paul, MN, EUA & Light cure for $20 \mathrm{~s}$ \\
\hline \multirow{2}{*}{ SBU-40 } & Single Bond & 3M/ESPE, St. & Rub primer on the tooth for $40 \mathrm{~s}$; Gently air-dry for $5 \mathrm{~s}$ \\
\hline & Universal (SBU) & Paul, MN, EUA & Light cure for $20 \mathrm{~s}$ \\
\hline
\end{tabular}




\section{SBS analysis}

The SBS was carried out as specified in ISO 11405, using a universal test machine (EMIC, DL2000, São José dos Pinhais, PR, Brasil) with a chisel at a crosshead speed of $0.5 \mathrm{~mm} / \mathrm{min}$ until failure. The force required to debonding the bracket was recorded in Newtons $(\mathrm{N})$ and was divided by the area of the base of the bracket $\left(\mathrm{mm}^{2}\right)$ and converted to Mega Pascal (MPa) (Jacker-Guhr et al., 2019).

\section{ARI analysis}

After the brackets were debonded, the enamel surface of each tooth was examined under $12.5 \mathrm{x}$ magnification using a stereomicroscope (Leica TCS-SL; Leica, Wetzlar, Germany) to determine the amounts of residual adhesive remaining on each tooth. To determine the ARI, specimens were digitally photographed, standardized in relation to scanner light level, contrast, exposure and saturation. The files were exported in JPEG format and analyzed by a single calibrated examiner - ImageJ $1.50 \mathrm{i}$ software (National Institutes of Health, USA). The ARI assessment was performed in darkness by a single and previously trained and calibrated examiner (kappa intra-examiner analysis $=1.0$ ).

The ARI was used to classify the failure modes as follow (Artun \& Bergland, 1984): score 0: no composite resin left on the dental tooth; score 1: less than half of the composite resin left on the dental tooth; score 2: more than half of the composite resin left on the dental tooth; and score 3: all composite resin left on the dental tooth, with a clear impression of the bracket mesh.

\section{Morphological Analysis of the Enamel}

Ten teeth of each group were randomly selected, removed from the PVC cylinders. Dental fragments were dehydrated in different ethanol concentrations (i.e., 70,80, 90, and 100\%) and placed in a blue silica container for 24 hours. The dental sections were fixed on metal stubs with double-sided adhesive carbon tape (Electron Microscopy Science) and sputter coated with gold/palladium (SCD 050; Balzer, Schaan, Liechtenstein). Morphological analyses of the enamel (after debonding) were carried out with a scanning electron microscope (SEM, JEOL JSM $6610 \mathrm{LV}$ ), operated at $20 \mathrm{kV}$, with a working distance of 15 $\mathrm{mm}$ and a spot size of 53. Magnification $(\times 200)$ was used to obtain representative images from the debonding surface. In representative regions were used $x 2000$ of magnification.

\section{Statistical Analysis}

The normality and homoscedasticity of the data were analyzed by the Kolmogorov-Smirnov test. Shear bond strength data were compared with one-way ANOVA and Tukey's post-hoc test $(P<0.05)$. The Kruskal-Wallis test was used to compare the ARI scores between the tested groups $(P<0.05)$. All analyses were performed using the software SPSS $^{\circledR} 14.0$ for Windows $^{\circledR}$ (SPSS Inc., Chicago, IL, USA).

\section{Results}

The SBS between groups was significant different $(P<0.001)$. T-SEP $(16.92 \pm 3.45 \mathrm{MPa})$ and P-XT $(17.27 \pm 3.63$ MPa) showed higher shear bond strength than SBU-20 (10.94 $\pm 3.24 \mathrm{MPa})$ and SBU-40 (8.41 $\pm 2.62 \mathrm{MPa})$ (Table 2). 
Table 2. Descriptive statistics and ANOVA results and Tukey test for resistance (MPa).

\begin{tabular}{ccc}
\hline Groups & Mean & Standard-deviation \\
\hline P-XT & $17.3^{\mathrm{A}}$ & 3.6 \\
T-SEP & $16.9^{\mathrm{A}}$ & 3.4 \\
SBU-20 & $10.9^{\mathrm{B}}$ & 3.2 \\
SBU-40 & $8.4^{\mathrm{B}}$ & 2.6 \\
\hline
\end{tabular}

* Different letters represent statistically significant differences by the Tukey test. Source: Personal archives (2021).

It was not observed a significant difference between the groups according to the ARI distribution (Figure 1, KruskalWallis test, $P=0,062$ ). The score 1 (less than half of resin composite bonded to teeth) was the most frequent in all tested groups.

Figure 1. Distribution of ARI scores according to groups.

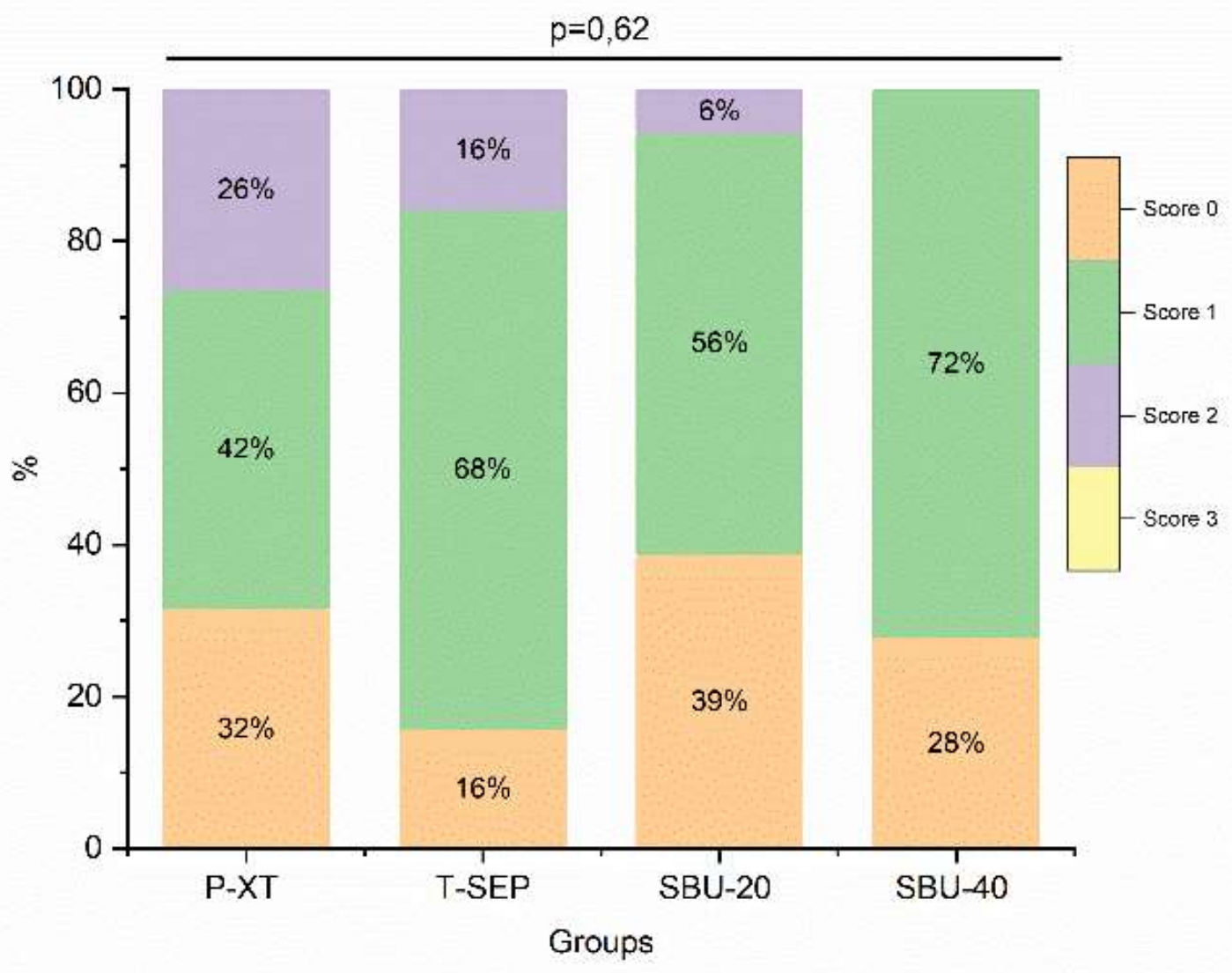

Source: Personal archives (2021).

SEM analysis showed that enamel damage was detected in T-SEP (Figure 2) and P-XT (Figure 3) groups. This is observed within the erosion zones formed by phosphoric acid (Figures 2 and 3 ). 
Research, Society and Development, v. 10, n. 13, e199101320832, 2021

(CC BY 4.0) | ISSN 2525-3409 | DOI: http://dx.doi.org/10.33448/rsd-v10i13.20832

Figure 2. Photomicrography of SEP-5 group.

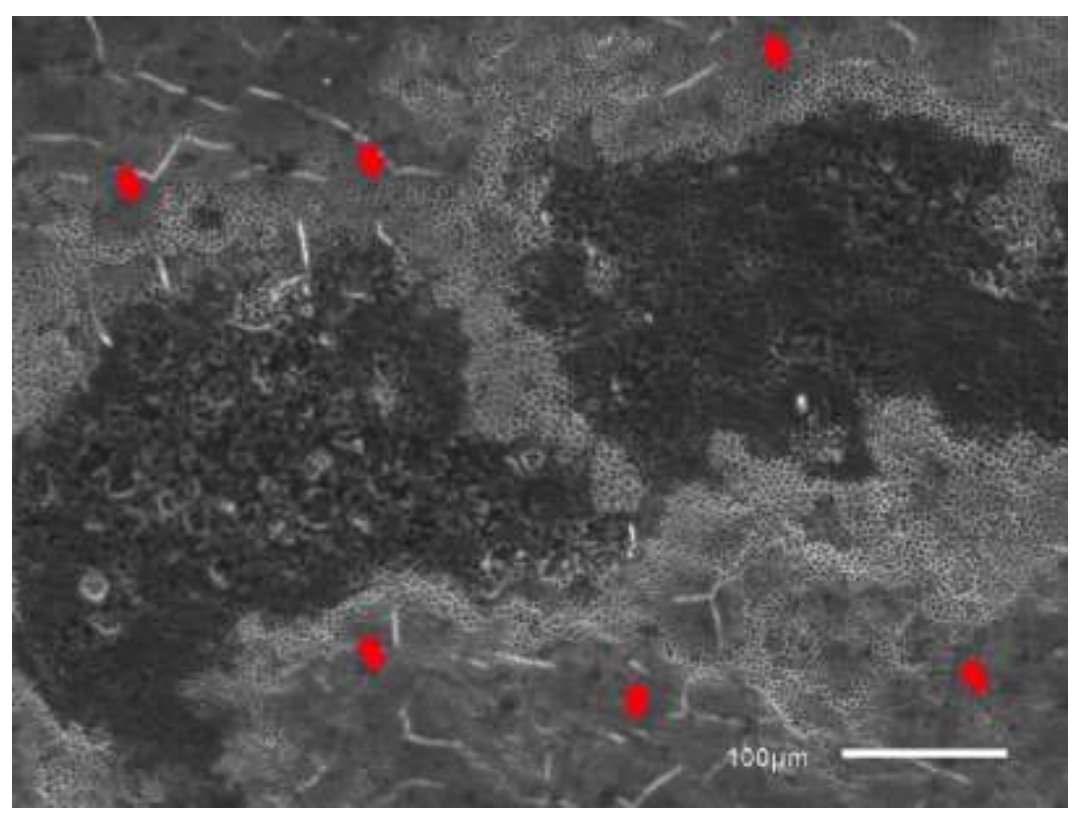

Enamel erosion zones formed by phosphoric acid are shown (area between the red arrows). Source: Personal archives (2021).

Figure 3. Photomicrography of P-XT group, demonstrated the presence of erosion zones.

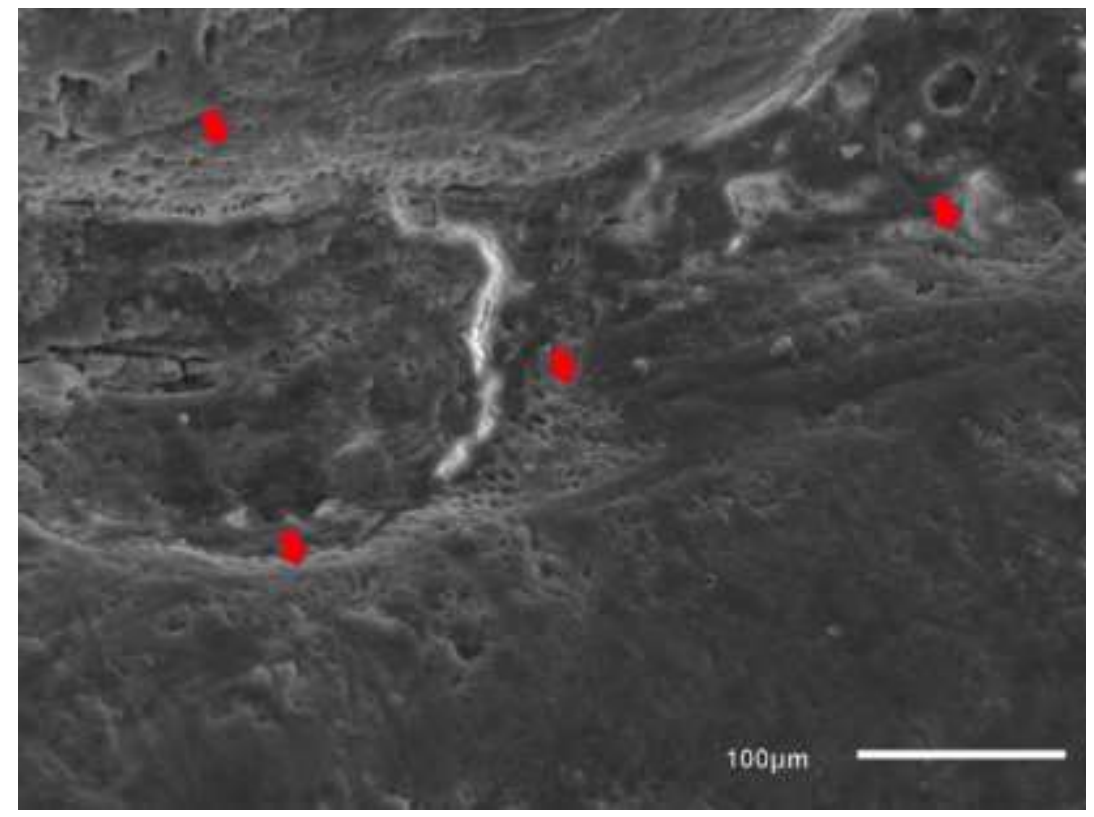

Source: Personal archives (2021).

In two specimens of the P-XT (Figure 4) group, small damages were observed at the dentin level. 
Research, Society and Development, v. 10, n. 13, e199101320832, 2021

(CC BY 4.0) | ISSN 2525-3409 | DOI: http://dx.doi.org/10.33448/rsd-v10i13.20832

Figure 4. Photomicrography at higher magnification in P-XT group, damages in dentin level, characterized by exposed dentinal tubules (red arrows).

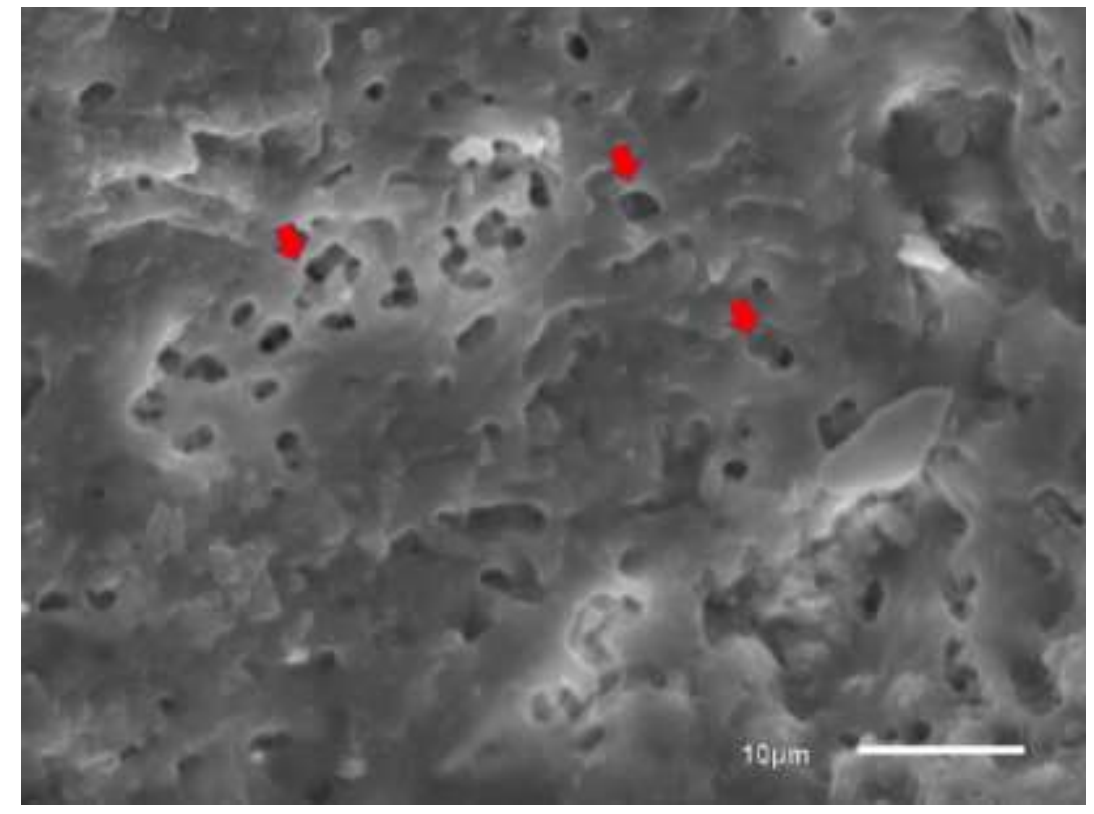

Source: Personal archives (2021).

Enamel was intact in all specimens of Groups SBU-20 (Figure 5) and SBU-40 (Figure 6).

Figure 5. Photomicrography of SBU-20 group.

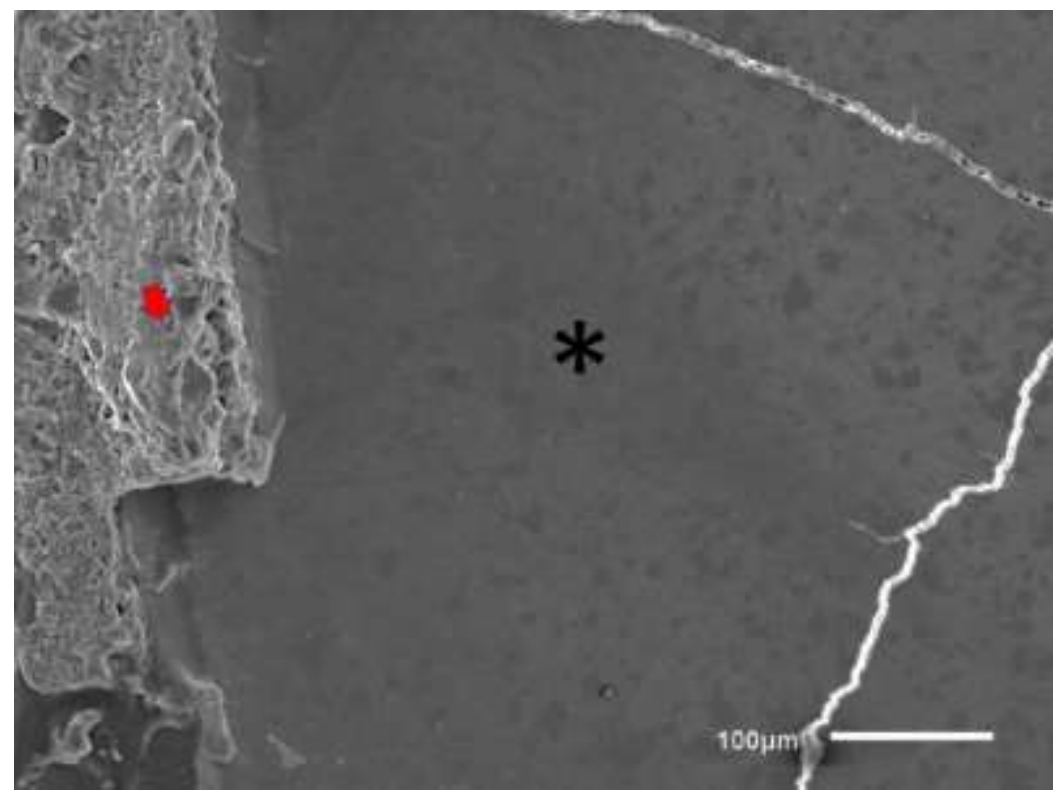

Enamel showing a healthy surface with no remarkable evidence of erosion $\left(^{*}\right)$. The bonding system is shown (red arrow). Source: personal archives (2021). 
Figure 6. Photomicrography of SBU-40 group, enamel exhibited a healthy surface (*), note the bonding system (red arrow).

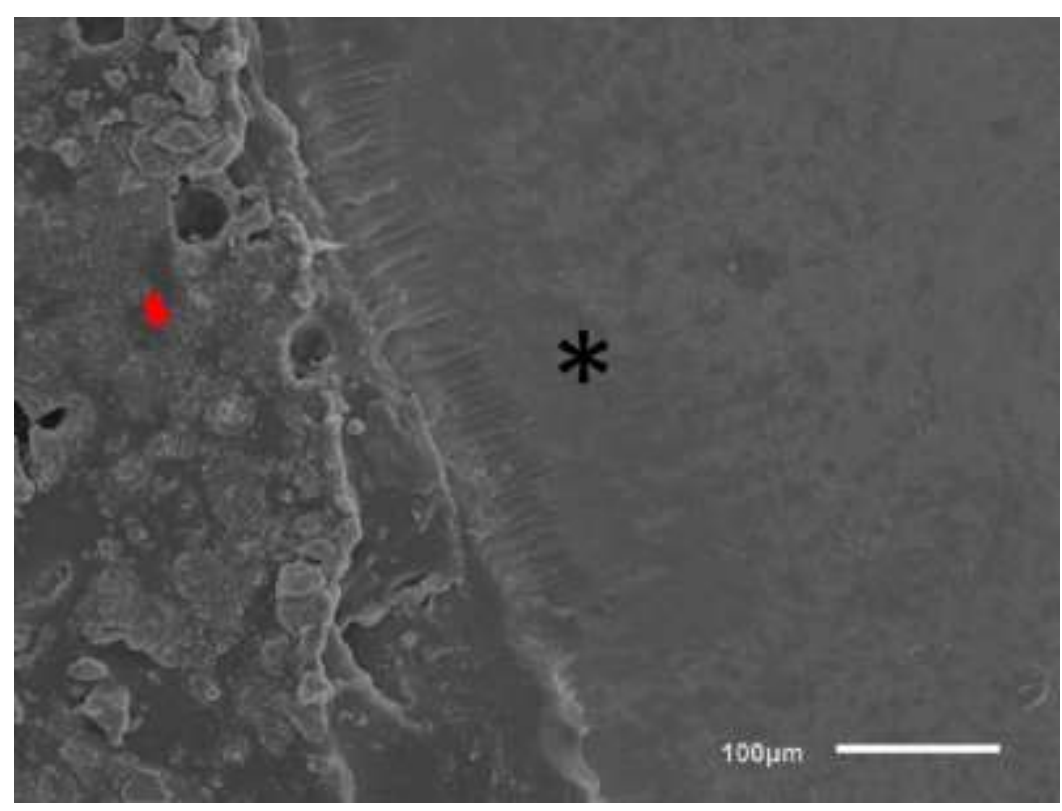

Source: Personal archives (2021).

\section{Discussion}

Our study showed that the conventional etch-and-rinse adhesive system, P-XT, and its self-etching version, T-SEP, produced a greater enamel bond strength than when using the universal adhesive SBU. Thus, our first null hypothesis must be rejected.

Previous studies also reported similar bracket-to-enamel SBS for P-XT and its self-etching version T-SEP (Seeliger et al., 2017, Yadala et al., 2014). T-SEP was delivered to the market for brackets bonding; however, it has the same chemical composition of Prompt-L-Pop —indicated for bond direct resin restorations. This adhesive presents the same acidity as phosphoric acid ( $\mathrm{pH} \cong$ around 1), producing also the same etching patterns (Di Hipólito et al., 2005). This acidity justifies the similar immediate bond values found for P-XT and T-SEP.

The SBS can be affected by different variables, such as adhesive composition, etching time, acidity of the etchant and brackets design (Ciocan et al., 2014). The prolonged application of universal adhesives is recognized as a viable alternative to increase the etching time and by consequence resin-enamel bond strength (Loguercio et al., 2015). This approach increases the contact of acidic resin monomers to enamel surface, creating a stable retentive pattern (Cardenas et al., 2017). Despite some authors reported improved enamel bond strength using these techniques — this is not consensual. It seems that other factors, such as the adhesive $\mathrm{pH}$, as well as the application technique for each adhesive may have influenced the bond strength (Kimmes et al., 2010, Shafiei et al., 2019).

In this context, self-etching adhesives are classified according to their $\mathrm{pH}$ in 'ultra-mild' ( $\mathrm{pH}>2.5$ ); 'mild' ( $\mathrm{pH} \approx 2$ ); 'intermediately strong' ( $\mathrm{pH}$ ranging from 1 to 2 ); 'strong' $(\mathrm{pH} \leq 1) \mathrm{SBU}$ is an 'ultra-mild' self-etching adhesive (i.e., $\mathrm{pH}=2.7$ ) (Almosa \& Zafar, 2018). SBU has a lower enamel etching potential compared to other types (Van Meerbeek et al., 2011). This fact could explain the lower immediate SBS of SBU to intact enamel. On the other hand, based on our results, we observed that, even though the SBU greater application time with the intact bovine enamel was not enough to promote greater retention with the bracket.

Regarding the ARI distribution between all groups showed no significant differences, thus, the second hypothesis has to be accepted. The score 1 (less than $50 \%$ of resin composite bonded to teeth) was the most frequent in all groups, as found previously (Rodríguez-Chávez et al., 2017). The advantage of this feature is that minimum amounts of resin are adhered to the 
enamel after debonding, reducing the required time to remove the residual adhesive. In the contrary, some reports suggested a potential enamel damage during debonding (Bosco et al., 2020), because its composition may promote more enamel damage when SBS values are higher (Cruz-González \& Delgado-Mejía, 2020).

Even though T-SEP and PTX presented higher SBS, they produced greater enamel damage after debonding, when compared with the other groups (SBU-20, SBU-40). While adequate bonding of a multibracket appliance seems to be critical for complication-free treatment, the integrity of the enamel surface after debonding is very important too, to dentists and patients. It has been suggested that the minimum SBS of 6.0 to $8.0 \mathrm{MPa}$ is adequate for bonding orthodontic brackets to teeth, which ensures that the bracket-adhesive-tooth bond remains intact (Mohammadi et al., 2018). As SBU is an 'ultra-mild' selfetch adhesive, it has a more superficial interaction than 'mild', 'intermediately strong', and 'strong'. This interaction occurs with dental substrate, and it is called "nano-interaction" (Carrilho et al., 2019). The ultra-mild interaction could explain the low damage caused by the SBU adhesive to enamel.

On the contrary, the phosphoric acid techniques are associated with a risk of enamel cracking during debonding, due to the aggressive etching pattern and the high adhesive penetration (Cehreli et al., 2005). However, the lower adhesive penetration was produced by T-SEP when 37\% phosphoric acid and a separate primer were used (Cehreli et al., 2005). When T-SEP was compared to SBU, a great discrepancy was observed. The interaction of T-SEP with the enamel is micrometric (between 1 and $2 \mu \mathrm{m}$ ) and for SBU is nanometric (few hundreds of nanometers) (Van Meerbeek et al., 2011) — justifying the lower damage for SBU. Furthemore, the SBU adhesive, contains a functional monomer, called 10-methacryloyloxyydecyl dihydrogen phosphate or 10-MDP, whose molecules and the polyalkenoic acids (as functional polymer in glass-ionomers) chemically bond to $\mathrm{Ca}+$ of HAp. The chemical reaction between these components form stable calcium phosphate and calcium carboxylate salts, respectively, along with only a limited surface-decalcification effect (Tian et al., 2017). In addition to reducing the number of operative steps SBU may reduce the equipment costs in orthodontics, and less materials are required to achieve equally effective adhesive bond strengths. Eliminating the acid etching followed by bonding, the risk of errors during application and the amount of chair time may be reduced (Cehreli et al., 2005).

In the present study, SBS of SBU adhesive ranged around $10 \mathrm{MPa}$. Based on security values for SBS (6 MPa and 8 MPa) (Alshahrani et al., 2018), it is possible to affirm that, that SBU offers adequate resistance to orthodontic fores and less risk of damage to the enamel in case of debonding. Future investigations on the SBU adhesion strength, for more time, and in clinical tests, could provide further insights to explain whether brackets bonded to teeth enamel will endure orthodontic forces.

\section{Conclusion}

The application of universal adhesives in the time recommended by the manufacturer ensure satisfactory bond strength and enamel integrity. Conventional P-XT and T-SEP adhesives had the highest shear bond strength, but they were associated with more enamel damage compared to universal adhesives.

\section{Acknowledgments}

Authors would like to thank the Ultra Cellular Structure Laboratory Carlos Alberto Redins (LUCAAR- UFES) for the SEM equipment and materials. Funding: None. Declarations of interest: None.

\section{References}

Almosa, N. \& Zafar, H. (2018). Incidence of orthodontic brackets detachment during orthodontic treatment: A systematic review. Pak J Med Sci, 34(3), 744750 .

Alshahrani, I., Abdelaziz, K., Asiry, M. A., AlShikh, A. J. A., AlGhamdi, W., \& Mansour, H. A. (2018). Effects of Different Stain Removal Protocols on 
Bonding Orthodontic Brackets to Enamel. J Contemp Dent Pract, 19(7), 762-767.

Artun, J., \& Bergland, S. (1984). Clinical trials with crystal growth conditioning as an alternative to acid-etch enamel pretreatment. Am J Orthod, 85(4), 333340 .

Bayar, B. H., \& Çokakoğlu, S. (2020). Effects of one-step orthodontic adhesive on microleakage and bracket bond strength: An in vitro comparative study. Int Orthod, 18(2), 366-373.

Bosco, E., Potrubacz, M. I., Arrizza, L., Chimenti, C., \& Tepedino, M. (2020). Enamel preservation during composite removal after orthodontic debonding comparing hydroabrasion with rotary instruments. Dent Mater J, 39(3), 367-374.

Cardenas, A. M., Siqueira, F., Rocha, J., Szesz, A. L., Anwar, M., El-Askary, F., Reis, A., Loguercio, A. (2016). Influence of Conditioning Time of Universal Adhesives on Adhesive Properties and Enamel-Etching Pattern. Oper Dent, 41(5), 481-490.

Carrilho, E., Cardoso, M., Marques, F. M., Marto, C. M., Paula, A., \& Coelho, A. S. (2019). 10-MDP Based Dental Adhesives: Adhesive Interface Characterization and Adhesive Stability-A Systematic Review. Materials (Basel), 12(5), 790.

Cehreli, Z. C., Kecik, D., \& Kocadereli, I. (2005). Effect of self-etching primer and adhesive formulations on the shear bond strength of orthodontic brackets. Am J Orthod Dentofacial Orthop, 127(5), 573-626.

Ciocan, D. I., Stanciu, D., Popescu, M. A., Miculescu, F., Plotog, I., Vărzaru, G., Ciocan, L. T. (2014). Electron microscopy analysis of different orthodontic brackets and their adhesion to the tooth enamel. Rom J Morphol Embryol, 55(2), 591-596.

Cruz-González, A. C., \& Delgado-Mejía, E. (2020). Experimental study of brackets adhesion with a novel enamel-protective material compared with conventional etching. Saudi Dent J, 32(1), 36-42.

Di Hipólito, V., de Goes, M. F., Carrilho, M. R., Chan, D. C., Daronch, M., Sinhoreti, M. A. (2005). SEM evaluation of contemporary self-etching primers applied to ground and unground enamel. J Adhes Dent, 7(3), 203-211.

Ibrahim, A. I., Al-Hasani, N. R., Thompson, V. P., \& Deb, S. (2020). In vitro bond strengths post thermal and fatigue load cycling of sapphire brackets bonded with self-etch primer and evaluation of enamel damage. J Clin Exp Dent, 12(1), e22-e30.

Jacker-Guhr, S., Sander, J., \& Luehrs, A. K. (2019). How "Universal" is Adhesion? Shear Bond Strength of Multi-mode Adhesives to Enamel and Dentin. J Adhes Dent, 21(1), 87-95.

Kimmes, N. S., Barkmeier, W. W., Erickson, R. L., \& Latta, M. A. (2010). Adhesive bond strengths to enamel and dentin using recommended and extended treatment times. Oper Dent, 35(1), 112-119.

Lamper, T., Ilie, N., Huth, K. C., Rudzki, I., Wichelhaus, A., \& Paschos, E. (2014). Self-etch adhesives for the bonding of orthodontic brackets: faster, stronger, safer? Clin Oral Investig, 18(1), 313-319.

Loguercio, A. D., Muñoz, M. A., Luque-Martinez, I., Hass, V., Reis, A., \& Perdigão, J. (2015). Does active application of universal adhesives to enamel in self-etch mode improve their performance? J Dent, 43(9), 1060-1070.

Meeran NA. (2013). Iatrogenic possibilities of orthodontic treatment and modalities of prevention. J Orthod Sci, 2(3), 73-86.

Mohammadi, A., Pourkhameneh, S., \& Sadrhaghighi, A. H. (2018). The effect of different force magnitudes for placement of orthodontic brackets on shear bond strength, in three adhesive systems. J Clin Exp Dent, 10(6), 548-554.

Perdigão, J., \& Swift, E. J.Jr. (2015). Universal Adhesives. J Esthet Restor Dent, 27(6), 331-334.

Rodríguez-Chávez, J. A., Arenas-Alatorre, J., \& Belio-Reyes, I. A. (2017). Comparative study of dental enamel loss after debonding braces by analytical scanning electron microscopy (SEM). Microsc Res Tech, 80(7), 680-686.

Seeliger, J. H., Botzenhart, U. U., Gedrange, T., Kozak, K., Stepien, L., \& Machoy, M. (2017). Enamel shear bond strength of different primers combined with an orthodontic adhesive paste. Biomed Tech (Berl), 62(4), 415-420.

Shafiei, F., Sardarian, A., Fekrazad, R., Farjood, A. (2019). Comparison of shear bond strength of orthodontic brackets bonded with a universal adhesive using different etching methods. Dental Press J Orthod, 24(4), 33-33.

Tian, F. C., Wang, X. Y., Huang, Q., Niu, L. N., Mitchell, J., Zhang, Z. Y., Prananik, C., Zhang, L., Chen, J. H., Breschi, L., Pashley, D. H., \& Tay, F. R. (2016). Effect of nanolayering of calcium salts of phosphoric acid ester monomers on the durability of resin-dentin bonds. Acta Biomater, 38, 190-200.

Van Meerbeek, B., Yoshihara, K., Yoshida, Y., Mine, A., De Munck, J., \& Van Landuyt, K. L. (2011). State of the art of self-etch adhesives. Dent Mater, 27(1), 17-28.

Velasquez, L. M., Sergent, R. S., Burgess, J. O., \& Mercante, D. E. (2006). Effect of placement agitation and placement time on the shear bond strength of 3 self-etching adhesives. Oper Dent, 31(4), 426-430.

Yadala, C., Gaddam, R., Arya, S., Baburamreddy, K. V., Raju, V. R., \& Varma, P. K. (2015). Comparison of Shear Bond Strength of Three Self-etching Adhesives: An In-Vitro Study. J Int Oral Health, 7(7), 53-57. 